\title{
Intervention with flaxseed and borage oil supplements modulates skin condition in women
}

\author{
Silke De Spirt ${ }^{1}$, Wilhelm Stahl ${ }^{1} *$, Hagen Tronnier $^{2}$, Helmut Sies ${ }^{1}$, Marie Bejot ${ }^{3}$, Jean-Marc Maurette ${ }^{3}$ \\ and Ulrike Heinrich ${ }^{2}$ \\ ${ }^{1}$ Institut für Biochemie und Molekularbiologie I, Heinrich-Heine-Universität Düsseldorf, P.O. Box 101007, D-40001 Düsseldorf, \\ Germany \\ ${ }^{2}$ Institut für Experimentelle Dermatologie, Universität Witten-Herdecke, Alfred-Herrhausen-Str. 44, D-58455 Witten, Germany \\ ${ }^{3}$ Laboratoire Oenobiol, 59 Boulevard Exelmans, Paris 75016, France
}

(Received 9 October 2007 - Revised 16 May 2008 - Accepted 21 May 2008 - First published online 2 September 2008)

Ingestion of selected nutrients modulates dermal properties. In the present study, two groups of women ingested flaxseed or borage oil for 12 weeks. The control group received a placebo containing medium-chain fatty acids. Dose was $2 \cdot 2 \mathrm{~g}$ total fatty acids/d with $\alpha$-linolenic acid and linoleic acid as major constituents in the flaxseed oil group; in the borage oil group linoleic and $\gamma$-linolenic acid were predominant. In the flaxseed oil group, the contribution of $\alpha$-linolenic acid to total fatty acids in plasma was significantly increased on weeks 6 and 12 , whereas there was an increase in $\gamma$-linolenic acid in the borage oil group $(P<0.05)$. Skin irritation was performed by nicotinate treatment, and changes in skin reddening and blood flow were monitored. Compared to week 0 , skin reddening was diminished in both groups; blood flow was also lowered. Skin hydration was significantly increased after 12 weeks of treatment compared to week 0 , with flaxseed or borage oil $(P<0.05)$. Transepidermal water loss was decreased in both oil groups by about $10 \%$ after 6 weeks of supplementation. A further decrease was determined after 12 weeks in the flaxseed oil group. Surface evaluation of living skin revealed that roughness and scaling of the skin were significantly decreased with flaxseed and borage oil comparing week 0 and week $12(P<0 \cdot 05)$. Except for hydration, none of the parameters was affected in the placebo group. The present data provide evidence that skin properties can be modulated by an intervention with dietary lipids.

Lipids: Skin: Human studies: Hydration: Blood flow

Basic skin functions like that of a shielding barrier, homeostasis of water, temperature regulation and photoprotection respond to supplementary or dietary intervention with selected nutrients $^{(1,2)}$. Modulated functions are accompanied by changes in cutaneous structure and texture which affect the appearance of the skin. Studies in man have shown that an increased intake of carotenoids such as $\beta$-carotene or lycopene, carotenoid-rich food or flavanol-rich cocoa strengthens the basal protection against UV-induced erythema, increases cutaneous blood flow, and modulates skin structure and hydration ${ }^{(3,4)}$.

Some PUFA are essential for the human organism and serve several biological functions. Supplementation with certain fatty acids can influence the fatty acid pattern of the skin and affect its sensitivity towards photooxidation ${ }^{(5)}$ and may contribute to prevention of non-melanoma cancers ${ }^{(6)}$.

PUFA, like linoleic acid (LA) or $\alpha$-linolenic acid (ALA) and $\gamma$-linolenic acid (GLA), play a role in cellular signalling interfering with eicosanoid pathways or influencing the regulation of gene expression ${ }^{(2,7)}$. Both $n-3$ as well as $n-6$ longchain PUFA are important components of cellular membranes, contributing to their fluidity, rigidity, permeability and function $^{(8,9)}$. Epidermal lipids are known to play an important role in mediating normal desquamation and deficiency of essential fatty acids has been reported to be involved in cutaneous scaling disorders such as senile xerosis, psoriasis and atopic dermatitis ${ }^{(10)}$.

The organism has a limited activity to generate higher PUFA from $\mathrm{C} 18$ fatty acids via desaturation-elongation reactions. Thus, the $n-6$ PUFA LA can be metabolized to GLA. However, it has been reported that cutaneous tissue lacks such activity ${ }^{(11)}$.

Based on structural effects and signalling processes, PUFA affect macroscopic properties of the skin essential for cutaneous health. Supplementation with LA and GLA from borage oil over a 2-month period leads to decreased transepidermal water loss (TEWL) and itching. Dry skin appearance was diminished significantly, but no alteration of skin hydration was measured ${ }^{(12)}$. LA deficiency results in deformation or absence of the lamellar bodies, giving way to water passing the epidermis ${ }^{(13)}$. Consumption of flaxseed oil rich in ALA or DHA/EPA-rich fish oil is associated with lower levels of proinflammatory eicosanoids ${ }^{(14)}$. In the present study we investigated the effects of 12 -week oral supplementation with flaxseed or borage oil on human skin properties.

Abbreviations: ALA, $\alpha$-linolenic acid; DGLA, di-homo- $\gamma$-linolenic acid; GLA, $\gamma$-linolenic acid; LA, linoleic acid; TEWL, transepidermal water loss.

* Corresponding author: Professor Dr Wilhelm Stahl, fax +49 211811 3029, email wilhelm.stahl@uni-duesseldorf.de 


\section{Materials and methods}

\section{Subjects and study design}

Forty-five female healthy non-smoking women, between 18 and 65 years, with sensitive and dry skin were recruited by the Institute of Experimental Dermatology, and selected according to their skin type: dry skin; Corneometer value $<40 \mathrm{au}^{(15)}$. Exclusion criteria were: pregnancy and breast-feeding, history of fat malabsorption, liver diseases, diseases regarding lipid metabolism or any photosensitizing disorder. BMI of the participants was between 18 and $25 \mathrm{~kg} / \mathrm{m}^{2}$, they did not take lipid or vitamin supplements or any other medication.

The study was performed as a monocentric, randomized, double-blind placebo-controlled application test, in three parallel treatment groups, consisting of fifteen persons each. Age distribution was comparable between the three groups. Four capsules with different oils were taken every day, two at breakfast and two at dinner. Daily doses amounted to $2 \cdot 2 \mathrm{~g}$ flaxseed or borage oil; in both groups, intake of tocopherol was $10 \mathrm{mg} / \mathrm{d}$. Daily intake of the placebo was also $2 \cdot 2 \mathrm{~g}$. The fatty acid pattern of flaxseed, borage oil and placebo are shown in Table 1.

Duration of the study was 12 weeks, measurements determining skin parameters and blood sampling was on day 0 , week 6 and week 12. All test subjects received detailed information listing every single parameter relevant to the study. Every test subject had to submit a written declaration of consent for their participation in the study.

\section{Fatty acid analysis}

Blood samples were collected into $10 \mathrm{ml} \mathrm{S}$-monovette tubes (Sarstedt, Nuemrecht, Germany) containing sodium EDTA as anticoagulant. After clotting, plasma was prepared by centrifugation $\left(10 \mathrm{~min} ; 4^{\circ} \mathrm{C}\right)$ at $3800 \mathrm{~g}$ and stored at $-80^{\circ} \mathrm{C}$ until analysis. Lipids were extracted according to Folch \& Lees ${ }^{(16)}$ with slight modifications. Plasma sample $(0.5 \mathrm{ml})$ was placed in a $10 \mathrm{ml}$ glass tube and mixed with $5 \mathrm{ml}$ chloroform-methanol (2:1), containing $200 \mathrm{mg} / \mathrm{l}$ butylated hydroxytoluene (BHT) as antioxidant. The sample was mixed by shaking at $37^{\circ} \mathrm{C}$ for $45 \mathrm{~min}$. After addition of $1 \mathrm{ml}$ sodium chloride solution $(0.9 \%)$ and centrifugation at $660 \mathrm{~g}$ for $10 \mathrm{~min}$ at $4^{\circ} \mathrm{C}$, the lipophilic layer was collected and washed twice

Table 1. Fatty acid composition of the supplements (\% of total fatty acids)

\begin{tabular}{lccc}
\hline Fatty acid & Flaxseed oil & Borage oil & Placebo \\
\hline $8: 0$ & 0.00 & 0.00 & 36.9 \\
$10: 0$ & 0.00 & 0.00 & 21.8 \\
$14: 0$ & 4.73 & 1.87 & 0.24 \\
$18: 0$ & 4.12 & 2.82 & 0.00 \\
$18: 1 n-9$ & 19.6 & 15.0 & 0.60 \\
$18: 2 n-6$ & 16.0 & 38.7 & 0.00 \\
$18: 3 n-6$ & 0.00 & 21.6 & 0.18 \\
$18: 3 n-3$ & 52.8 & 0.38 & 0.00 \\
$20: 0$ & 0.16 & 0.21 & 0.00 \\
$20: 1$ & 0.20 & 3.95 & 0.00 \\
$20: 2$ & 0.00 & 0.23 & 0.00 \\
$22: 1$ & 0.00 & 2.23 & 0.00 \\
$24: 0$ & 0.00 & 0.00 & 0.00 \\
$24: 1$ & 0.00 & 1.30 & 0.00 \\
Non-identified fatty acids & 2.39 & 11.7 & 40.3 \\
\hline
\end{tabular}

with $500 \mu \mathrm{l}$ methanol-sodium chloride $(0.9 \%)$-chloroform $(48: 47: 3)$. The solution was dried under a stream of nitrogen. For base-catalysed transesterification to yield fatty acid methyl esters the fat extract was incubated $1 \mathrm{~h}$ at $60^{\circ} \mathrm{C}$ with $3 \mathrm{ml}$ water-free methanol containing sodium methoxide $(3 \%$ $\mathrm{m} / \mathrm{v})$. Chlorogenic acid $(1 \mathrm{ml})$ was added, and fatty acid methyl esters were extracted twice with $3 \mathrm{ml}$ hexane, concentrated under nitrogen to a final volume of $350 \mu \mathrm{l}$ and transferred to an injection vial sealed with a metal cap. Fatty acid methyl esters were separated by GC on a FFAP column (Crossbond Carbowax PEG for acid compounds; $30 \mathrm{~m}$, $250 \mu \mathrm{m}$ ) and detected by flame ionization (Clarius $500 \mathrm{PE}$ AutoSystem with built-in autosampler; Perkin Elmer, Shelton, USA). The injector temperature was $240^{\circ} \mathrm{C}$, the oven temperature programme started at $150^{\circ} \mathrm{C}$ and increased continuously to $190^{\circ} \mathrm{C}$ at a rate of $20^{\circ} \mathrm{C} / \mathrm{min}$ and from 190 to $235^{\circ} \mathrm{C}$ at a rate of $1^{\circ} \mathrm{C} / \mathrm{min}$ with a final hold of $35 \mathrm{~min}$. Nitrogen was used as carrier gas at a pressure of $70 \mathrm{kPa}$. Detector temperature was $260^{\circ} \mathrm{C}$. Peak identification was with authentic fatty acid methyl ester standards (Supelco, Deisenhofen; Fluka; Sigma, St. Louis, MO, USA). With this procedure all esterified fatty acids are detected and referred to as 'total fatty acids'. The relative amount of each fatty acid was calculated from the ratio of the area under the signal and total area of all identified fatty acid methyl esters (100\% method).

\section{Skin sensitivity}

Nicotinate irritation was used to test the sensitivity of the skin according to Primavera \& Berardesca ${ }^{(17)}$. Measurements were performed on the inner forearm of the volunteers. No treatment with any ointment on the tested areas was allowed during the whole study. Nicotinate $\left(0.25 \% ; 5 \mu \mathrm{l} / \mathrm{cm}^{2}\right)$ was applied inducing an inflammation of the skin; reddening was measured by chromametry as $a$ value (Minolta CR 300, Ahrensburg, Germany) before and after treatment. Erythema intensity is given as $\Delta a$ value; $a$ value after treatment minus $a$ value before treatment. Additionally, capillary blood flow was determined by Laser-Doppler-Flowmetry (O2C- System; Lea Instruments, Giessen, Germany) in the irritated area.

\section{Skin hydration and transepidermal water loss}

Skin hydration (arbitrary units) was determined by corneometry (Corneometer CM 825; Courage \& Khazaka Electronics, Cologne, Germany); TEWL ( $\mathrm{g} / \mathrm{h}$ per $\mathrm{m}^{2}$ ) was measured using a TEWA-Meter TM 300 (Courage \& Khazaka Electronics) ${ }^{(15,18)}$.

\section{Evaluation of skin surface}

Skin surface profiles were evaluated with the surface evaluation of living skin method (Visioscan; Courage \& Khazaka Electronics) in a $15 \times 17 \mathrm{~mm}$ area. Four different parameters are applied to characterize skin surface: roughness, scaling, smoothness, wrinkles ${ }^{(19)}$.

\section{Statistics}

For all parameters and all time-points (week 0, week 6, week 12) descriptive statistics (means and standard deviations) were 
calculated. For all parameters pre-post differences were calculated and analysed descriptively.

Separately for each of the two pre-post differences 'week 6 - week 0' and 'week 12 - week 0' an ANOVA with the parameter treatment as the independent variable was performed. Tests for the treatment effect and the contrasts were performed. The least square means for the pre-post differences and the respective $95 \%$ CI were calculated. These CI were used to assess whether the pre-post difference was significantly different from zero.

\section{Results}

\section{Fatty acid analysis}

Fatty acid patterns of the supplements are shown in Table 1. In flaxseed oil, ALA is predominant; also considerable amounts of LA are present. The latter is the major fatty acid in borage oil followed by GLA. Thus, in flaxseed oil $n-3$ fatty acids contribute more than $50 \%$ to total fatty acid content, whereas more than $50 \%$ of fatty acids in borage oil are of the $n-6$ type. Additionally, both supplements contained similar amounts of tocopherol. Medium-chain fatty acids were present in the placebo; caprylic and capric acid were dominating. Volunteers were divided into three groups, flaxseed, borage and placebo, ingesting four capsules of the supplement per day over a period of 12 weeks. Daily doses amounted to $2.2 \mathrm{~g}$ flaxseed or borage oil; in both groups, intake of tocopherol was $10 \mathrm{mg} / \mathrm{d}$. Daily dose of the placebo was $2 \cdot 2 \mathrm{~g}$.

Blood samples were collected on day 0 , week 6 and week 12 and fatty acid composition of plasma lipids (total fatty acids) was analysed by GC. Results for the different groups are shown in Tables 2-4. In the flaxseed oil group, only the contribution of ALA to total fatty acids was significantly changed. From day 0 to week 6 it increased from 0.58 to $0.83 \%$ and remained constant until week 12. Upon supplementation with borage oil, the relative amount of GLA was significantly increased on weeks 6 and 12 compared to day 0. A marginal increase was detectable for di-homo- $\gamma$-linolenic acid (DGLA) from $2.09 \%$ in week 0 to $2.44 \%$ in week 6 and $2.33 \%$ in week 12. A significant decrease of DGLA was found in the

Table 2. Fatty acid composition of plasma lipids (\% total fatty acids) in the group treated with flaxseed oil $(n 15) \dagger$

(Mean values and standard deviations)

\begin{tabular}{|c|c|c|c|c|c|c|}
\hline \multirow[b]{3}{*}{ Fatty acid } & \multicolumn{6}{|c|}{ Time (weeks) } \\
\hline & \multicolumn{2}{|c|}{0} & \multicolumn{2}{|c|}{6} & \multicolumn{2}{|c|}{12} \\
\hline & Mean & SD & Mean & SD & Mean & SD \\
\hline $18: 2 n-6$ & 32.4 & 3.4 & $32 \cdot 7$ & $4 \cdot 9$ & $32 \cdot 3$ & 5.9 \\
\hline $18: 3 n-6$ & 0.59 & 0.27 & 0.53 & 0.19 & 0.55 & 0.19 \\
\hline $20: 3 n-6$ & 1.88 & 0.41 & 1.82 & 0.43 & 1.83 & 0.36 \\
\hline $20: 4 n-6$ & $7 \cdot 23$ & $1 \cdot 15$ & $6 \cdot 90$ & $1 \cdot 13$ & $6 \cdot 91$ & 1.06 \\
\hline $22: 4 n-6$ & 0.10 & 0.07 & 0.12 & 0.08 & 0.08 & 0.08 \\
\hline $18: 3 n-3$ & 0.58 & 0.21 & $0.83^{*}$ & 0.25 & $0 \cdot 84^{*}$ & 0.24 \\
\hline $20: 5 n-3$ & 0.85 & 0.38 & 0.88 & 0.31 & 0.97 & 0.37 \\
\hline $22: 5 n-3$ & 0.44 & 0.12 & 0.42 & 0.08 & 0.42 & 0.16 \\
\hline $22: 6 n-3$ & $1 \cdot 36$ & 0.60 & $1 \cdot 20$ & 0.31 & $1 \cdot 24$ & 0.40 \\
\hline
\end{tabular}

Mean values were significantly different from those of week 0 : ${ }^{*} P<0.05$.

†For details of procedures and supplements, see Materials and methods section and Table 1.
Table 3. Fatty acid composition of plasma lipids (\% total fatty acids) in the group treated with borage oil $(n 15) \dagger$

(Mean values and standard deviations)

\begin{tabular}{|c|c|c|c|c|c|c|}
\hline \multirow[b]{3}{*}{ Fatty acid } & \multicolumn{6}{|c|}{ Time (weeks) } \\
\hline & \multicolumn{2}{|c|}{0} & \multicolumn{2}{|c|}{6} & \multicolumn{2}{|c|}{12} \\
\hline & Mean & SD & Mean & SD & Mean & SD \\
\hline $18: 2 n-6$ & $31 \cdot 3$ & $4 \cdot 7$ & $28 \cdot 6$ & $9 \cdot 0$ & $31 \cdot 1$ & $5 \cdot 6$ \\
\hline $18: 3 n-6$ & 0.47 & 0.14 & $0.70^{*}$ & 0.21 & $0.64^{*}$ & 0.25 \\
\hline $20: 3 n-6$ & 2.09 & 0.40 & $2 \cdot 44^{*}$ & 0.57 & $2 \cdot 33^{*}$ & 0.59 \\
\hline $20: 4 n-6$ & $7 \cdot 62$ & 1.42 & $8 \cdot 11$ & 1.78 & $7 \cdot 82$ & 1.36 \\
\hline $22: 4 n-6$ & 0.17 & 0.08 & 0.14 & 0.10 & 0.12 & $0 \cdot 10$ \\
\hline $18: 3 n-3$ & 0.50 & 0.13 & $0.58^{*}$ & 0.11 & 0.52 & 0.12 \\
\hline $20: 5 n-3$ & 0.73 & 0.70 & 0.70 & 0.46 & 0.72 & 0.85 \\
\hline $22: 5 n-3$ & 0.37 & 0.12 & 0.35 & 0.19 & 0.35 & 0.13 \\
\hline $22: 6 n-3$ & 1.33 & 0.65 & $1 \cdot 31$ & 0.51 & $1 \cdot 29$ & 0.62 \\
\hline
\end{tabular}

Mean values were significantly different from those of week $0:{ }^{*} P<0.05$.

$\dagger$ For details of procedures and supplements, see Materials and methods section and Table 1.

placebo group comparing week 12 to week 0 . In none of the groups did vitamin E plasma levels change significantly (data not shown).

\section{Skin sensitivity}

Exposure of skin to nicotinate leads to chemically induced inflammation. The resulting erythema was evaluated by chromametry where $a$ values are a measure for skin reddening. The difference in $a$ values ( $\Delta a$ values) before and after exposure to nicotinate is shown in Table 5. Decreasing $\Delta a$ values are indicative for anti-inflammatory effects. Compared to baseline, $\Delta a$ values were significantly lower on weeks 6 and 12 in the groups treated with flaxseed and borage oil; after 12 weeks the decrease was 45 and $35 \%$, respectively $(P<0 \cdot 05)$. No changes were observed in the placebo group. However, it has to be noted that the basal value in the placebo group was lower than in the other groups.

Changes in the flaxseed oil group were signifcantly different from the placebo group (weeks $0-6, P=0.01$; weeks $0-12, P=0.006)$. Also the changes in the borage oil

Table 4. Fatty acid composition of plasma lipids (\% total fatty acids) in the group treated with placebo oil $(n 15) \dagger$

(Mean values and standard deviations)

\begin{tabular}{|c|c|c|c|c|c|c|}
\hline \multirow[b]{3}{*}{ Fatty acid } & \multicolumn{6}{|c|}{ Time (weeks) } \\
\hline & \multicolumn{2}{|c|}{0} & \multicolumn{2}{|c|}{6} & \multicolumn{2}{|c|}{12} \\
\hline & Mean & SD & Mean & SD & Mean & SD \\
\hline $18: 2 n-6$ & $32 \cdot 3$ & 4.4 & $31 \cdot 6$ & $5 \cdot 3$ & 31.4 & $4 \cdot 7$ \\
\hline $18: 3 n-6$ & 0.49 & $0 \cdot 16$ & 0.51 & 0.23 & 0.47 & 0.16 \\
\hline $20: 3 n-6$ & 2.03 & 0.30 & 1.92 & 0.32 & $1 \cdot 81^{*}$ & 0.37 \\
\hline $20: 4 n-6$ & $7 \cdot 49$ & 1.65 & $7 \cdot 16$ & 1.59 & $7 \cdot 71$ & $2 \cdot 01$ \\
\hline $22: 4 n-6$ & 0.09 & 0.09 & 0.11 & 0.07 & 0.10 & 0.08 \\
\hline $18: 3 n-3$ & 0.64 & 0.20 & 0.62 & 0.17 & 0.54 & 0.12 \\
\hline $20: 5 n-3$ & 0.68 & 0.29 & 0.79 & 0.32 & 0.69 & 0.47 \\
\hline $22: 5 n-3$ & 0.38 & $0 \cdot 11$ & 0.39 & $0 \cdot 10$ & 0.36 & 0.12 \\
\hline $22: 6 n-3$ & $1 \cdot 23$ & 0.41 & $1 \cdot 30$ & 0.48 & 1.40 & 0.65 \\
\hline
\end{tabular}

Mean values were significantly different from those of week $0:{ }^{*} P<0.05$.

$\dagger$ For details of procedures and supplements, see Materials and methods section and Table 1. 
Table 5. Sensitivity of skin to nicotinate-induced irritation in women supplemented with flaxseed or borage oil: intensity of erythema and cutaneous blood flow (arbitrary units; $n$ 15) $\dagger$

(Mean values and standard deviations)

\begin{tabular}{|c|c|c|c|c|c|c|}
\hline & \multicolumn{6}{|c|}{ Time (weeks) } \\
\hline & \multicolumn{2}{|c|}{0} & \multicolumn{2}{|c|}{6} & \multicolumn{2}{|c|}{12} \\
\hline & Mean & SD & Mean & SD & Mean & SD \\
\hline \multicolumn{7}{|l|}{$\Delta a$ value } \\
\hline Flaxseed oil & $4 \cdot 3$ & $1 \cdot 3$ & $2 \cdot 9^{*}$ & 0.9 & $2 \cdot 4^{*}$ & 1.0 \\
\hline Borage oil & $4 \cdot 2$ & 1.5 & $3 \cdot 0^{*}$ & 1.6 & $2 \cdot 7^{\star}$ & $1 \cdot 2$ \\
\hline Placebo & 3.4 & 1.0 & $3 \cdot 4$ & $1 \cdot 3$ & $3 \cdot 3$ & $1 \cdot 2$ \\
\hline \multicolumn{7}{|c|}{ Cutaneous blood flow } \\
\hline Flaxseed oil & $75 \cdot 0$ & $22 \cdot 0$ & $50 \cdot 0^{*}$ & $23 \cdot 0$ & $14 \cdot 0^{*}$ & $12 \cdot 0$ \\
\hline Borage oil & $71 \cdot 0$ & $20 \cdot 0$ & $51 \cdot 0^{\star}$ & $30 \cdot 0$ & $47 \cdot 0^{\star}$ & $20 \cdot 0$ \\
\hline Placebo & $70 \cdot 0$ & $22 \cdot 0$ & 63.0 & $26 \cdot 0$ & $64 \cdot 0$ & $29 \cdot 0$ \\
\hline
\end{tabular}

Mean values were significantly different from those of week $0:{ }^{*} P<0.05$.

$\dagger$ For details of procedures and supplements, see Materials and methods section and Table 1.

group significantly differed compared to the placebo group (weeks $0-6, P=0.03$; weeks $0-12, P=0.03$ ). There was no statistically significant difference between both groups treated with plant oils.

Inflammation of the skin is characterized by an increased cutaneous blood flow which is at least in part responsible for reddening. In parallel to decreasing $\Delta a$ values, cutaneous blood flow, compared to baseline, was lower in the groups receiving flaxseed and borage oil after 6 and 12 weeks of supplementation (Table 5). No change was observed in the placebo group. After 12 weeks the effect was more pronounced in the group that ingested flaxseed oil $(-82 \%)$ compared to the borage oil group $(-34 \%)(P<0.05)$. The changes in the flaxseed oil group were significantly different from the borage oil and the placebo group (weeks $0-12, P=0.00001$ and $P=0.002$, respectively).

\section{Skin hydration and transepidermal water loss; skin structure}

In women supplemented with flaxseed or borage oil, skin hydration was significantly increased after 12 weeks of treatment compared to day 0 (Table 6). In the flaxseed oil

Table 6. Effects on skin hydration and transepidermal water loss (TEWL) following supplementation with flaxseed or borage oil $(n 15) \dagger$ (Mean values and standard deviations)

\begin{tabular}{|c|c|c|c|c|c|c|}
\hline & \multicolumn{6}{|c|}{ Time (weeks) } \\
\hline & \multicolumn{2}{|c|}{0} & \multicolumn{2}{|c|}{6} & \multicolumn{2}{|c|}{12} \\
\hline & Mean & SD & Mean & SD & Mean & SD \\
\hline \multicolumn{7}{|c|}{ Hydration (arbitrary units) } \\
\hline Flaxseed oil & $32 \cdot 0$ & $8 \cdot 0$ & $35 \cdot 0^{*}$ & $10 \cdot 0$ & $38 \cdot 0^{*}$ & $7 \cdot 0$ \\
\hline Borage oil & $30 \cdot 0$ & $7 \cdot 0$ & $32 \cdot 0$ & $6 \cdot 0$ & $35 \cdot 0^{*}$ & $7 \cdot 0$ \\
\hline Placebo & $29 \cdot 0$ & $5 \cdot 0$ & $30 \cdot 0$ & $5 \cdot 0$ & $32 \cdot 0^{*}$ & $5 \cdot 0$ \\
\hline \multicolumn{7}{|c|}{ TEWL $\left(\mathrm{g} / \mathrm{h}\right.$ per $\left.\mathrm{m}^{2}\right)$} \\
\hline Flaxseed oil & $9 \cdot 7$ & $1 \cdot 1$ & $9 \cdot 0^{*}$ & $1 \cdot 1$ & $7 \cdot 2^{*}$ & $1 \cdot 8$ \\
\hline Borage oil & $9 \cdot 9$ & 0.8 & $9 \cdot 0^{*}$ & $1 \cdot 1$ & $8 \cdot 8^{*}$ & $1 \cdot 2$ \\
\hline Placebo & $9 \cdot 7$ & $1 \cdot 2$ & $9 \cdot 7$ & 1.5 & $9 \cdot 6$ & 1.6 \\
\hline
\end{tabular}

Mean values were significantly different from those of week $0:{ }^{*} P<0.05$.

†For details of procedures and supplements, see Materials and methods section and Table 1. group the effect was already seen after 6 weeks. A significant increase in skin hydration was also observed in the placebo group but only after 12 weeks. The increases observed for the plant oils were not significantly different from the placebo group.

TEWL was decreased in both plant oil groups by about $10 \%$ after 6 weeks. A further decrease was determined after 12 weeks in the flaxseed oil group, whereas there was only small difference in TEWL values between weeks 6 and 12 in the borage oil group. No statistically significant differences between day 0 and weeks 6 and 12 were measured in the placebo group. The change in the flaxseed oil group from weeks 0 to 12 was significantly different to the placebo group $(P=0.00006)$ and to the borage oil group $(P=0.01)$.

Skin profiles were analysed using the surface evaluation of living skin method which provides parameters associated with roughness, scaling, smoothness and wrinkling of the skin. Upon intervention for 12 weeks with flaxseed oil, roughness, scaling and smoothness were improved (Table 7). Supplementation with borage oil caused modifications in the same parameters, but only the decrease in scaling from week 0 to week 6 was statistically significant. No changes were determined in the placebo group except for a small but statistically significant decrease in the parameter smoothness. None of the treatments affected wrinkling.

Comparing groups, there was a significant difference between flaxseed oil and placebo for the parameter roughness (weeks $0-12, P=0.006$ ) and smoothness (weeks 0-6, $P=0.002$; weeks $0-12, P=0 \cdot 02$ ).

\section{Discussion}

Flaxseed oil, also known as linseed oil, derived from the seeds of the flax plant (Linum usitatissimum), is one of richest

Table 7. Parameters related to skin structure determined by surface evaluation of the skin at weeks 0,6 and 12 of the study (arbitrary units; $n$ 15)†

(Mean values and standard deviations)

\begin{tabular}{|c|c|c|c|c|c|c|}
\hline & \multicolumn{6}{|c|}{ Time (weeks) } \\
\hline & \multicolumn{2}{|c|}{0} & \multicolumn{2}{|c|}{6} & \multicolumn{2}{|c|}{12} \\
\hline & Mean & SD & Mean & SD & Mean & SD \\
\hline \multicolumn{7}{|l|}{ Roughness } \\
\hline Flaxseed oil & $1 \cdot 27$ & 0.40 & $1.07^{*}$ & 0.43 & $0.84^{\star}$ & 0.40 \\
\hline Borage oil & 1.43 & 0.61 & $1 \cdot 32$ & 0.56 & $1 \cdot 22$ & 0.42 \\
\hline Placebo & $1 \cdot 19$ & 0.25 & $1 \cdot 20$ & 0.21 & $1 \cdot 20$ & 0.35 \\
\hline \multicolumn{7}{|l|}{ Scaling } \\
\hline Flaxseed oil & 0.69 & 0.33 & $0.49^{\star}$ & 0.28 & $0.45^{\star}$ & 0.29 \\
\hline Borage oil & 0.59 & 0.33 & $0.44^{*}$ & 0.11 & 0.43 & 0.11 \\
\hline Placebo & 0.59 & 0.37 & 0.57 & 0.33 & 0.52 & 0.24 \\
\hline \multicolumn{7}{|l|}{ Wrinkles } \\
\hline Flaxseed oil & $35 \cdot 0$ & $2 \cdot 1$ & 34.6 & $2 \cdot 3$ & $35 \cdot 0$ & $2 \cdot 2$ \\
\hline Borage oil & $35 \cdot 2$ & 2.9 & 35.5 & $2 \cdot 7$ & $35 \cdot 6$ & $2 \cdot 8$ \\
\hline Placebo & $35 \cdot 2$ & 3.6 & $35 \cdot 8$ & $2 \cdot 6$ & $35 \cdot 8$ & $2 \cdot 7$ \\
\hline \multicolumn{7}{|l|}{ Smoothness } \\
\hline Flaxseed oil & $37 \cdot 2$ & $6 \cdot 1$ & $39 \cdot 1^{*}$ & 5.5 & $38.9^{*}$ & $5 \cdot 7$ \\
\hline Borage oil & $38 \cdot 2$ & $7 \cdot 7$ & $38 \cdot 1$ & $6 \cdot 4$ & 39.2 & $6 \cdot 7$ \\
\hline Placebo & $35 \cdot 8$ & $6 \cdot 4$ & $34 \cdot 3^{*}$ & $6 \cdot 2$ & $35 \cdot 0$ & $5 \cdot 8$ \\
\hline
\end{tabular}

Mean values were significantly different from those of week $0:{ }^{\star} P<0.05$.

†For details of procedures and supplements, see Materials and methods section and Table 1. 
sources of $n-3$ fatty acid. With more than $50 \%$ of total fatty acid, ALA is predominant but also the $n-6$ LA (16\%) and the monounsaturated oleic acid $(20 \%)$ are major constituents (Table 1). The flaxseed oil supplement used in the present study is typical with respect to its composition of fatty acids $^{(20)}$. Borage oil is produced from the seeds of the borage plant (Borago officinalis) and is rich in the $n-6$ fatty acids GLA (22\%) and LA (39\%); oleic acid $(15 \%)$ is also present in quite high amounts (Table 1). Also this supplement is typical regarding its fatty acid pattern ${ }^{(12)}$.

Ingestion of ALA-rich flaxseed oil or GLA-rich borage oil led to increases in the contribution of the respective fatty acid to total plasma lipids (Tables 2-4). Changes in other fatty acids were not observed, apart from increases in DGLA in the group supplemented with borage oil. DGLA is likely formed from GLA by an elongase-catalysed twocarbon chain elongation. In addition to elongases, desaturases are required for the synthesis of arachidonic acid and higher homologues of the $n-6$ family as well as for C20 PUFA of the $n-3$ family. Increases of C20 PUFA in plasma and different lipid fraction in the blood have been shown after application of high doses of $\mathrm{ALA}^{(21)}$. In the present study the total dose of ALA and GLA was quite low and thus changes in the levels of longer-chain fatty acids may have been too small for detection. It should be further noted that the pattern of plasma lipids does not necessarily reflect the lipid composition of tissues such as skin. Some major effects observed here are likely due to more significant changes in skin lipids. However, dermal punch biopsy would be required to analyse the fatty acid pattern at the target site.

The irritating effects of nicotinate were ameliorated by long-term intake of either flaxseed or borage oil (Table 5). Reddening of the skin after the chemical challenge was lower in both groups after 6 and 12 weeks of intervention. Similar effects have been described after intake of longchain $n$-3 fatty acids ${ }^{(5)}$. Supplementation with dietary fish oil diminished UV-B erythemal sensitivity in man. Although the mechanism of protection is not clear, it has been speculated that interferences with inflammatory pathways are important. In this context it is interesting to note that in the present study both supplements were active, although cutaneous blood flow was more affected by flaxseed oil. Therefore, it might be speculated that the contribution of PUFA on membrane and cell structure is at least in part responsible for the prevention of exogenous damage.

The function of selected C20 PUFA as precursors of eicosanoids for the synthesis of leukotrienes and PG may also play a role. This is in concordance with the effects of borage oil. GLA may be elongated to DGLA, which is metabolized to PG of the series 1 and to 15-hydroxyeicosatrienoic acid. Products of these eicosanoids mediate anti-inflammatory and antiproliferative effects ${ }^{(11)}$. However, ALA cannot be metabolized to anti-inflammatory eicosanoids in tissues lacking desaturases $^{(11)}$. Thus, other mechanisms are likely operative. Long-chain $n$-3 fatty acids decrease the generation of inflammatory cytokines, the expression of adhesion molecules and probably the generation of reactive oxygen species ${ }^{(22)}$. The influence of ALA in these pathways is unclear. A study with murine macrophages has shown that ALA down-regulates inflammatory inducible nitric oxide synthase, cyclooxygenase- 2 and $\mathrm{TNF}-\alpha$ gene expression interfering with $\mathrm{NF}-\mathrm{\kappa B}$ and mitogen-activated protein kinase ${ }^{(23)}$. DGLA lowers TNF- $\alpha$ and IL-10 levels in isolated human peripheral blood mononuclear cells ${ }^{(24)}$.

Stabilizing effects and improvements of cellular membranes may be responsible for changes of macroscopic skin properties related to water homeostasis. Again, with both supplements skin hydration was increased after 12 weeks of intervention, whereas TEWL was lower than control. Improvement of skin moisture and TEWL as well as firmness, indications for an improved barrier function, have been described after the intake of GLA-rich primrose and borage oil ${ }^{(25)}$. Skin hydration slightly increased in the placebo group. However, this was not accompanied by a decrease in TEWL. External factors maybe responsible for this minor effect.

There have been several approaches to modulate skin parameters with respect to influencing skin appearance under cosmetic aspects. With the surface evaluation of living skin method one can evaluate the skin structure and obtain information on roughness, scaling and wrinkling. Intervention with flaxseed or borage oil led to changes in roughness and scaling, which might be in part explained by the observed modulation of skin hydration and firmness. However, a parameter such as wrinkling, which results mainly from changes in the molecular structure of extracellular components, was not affected by any of the treatments.

It has been shown that under conditions of LA deficiency, LA is substituted by oleic acid in epidermal acylceramides ${ }^{(26)}$, which has been associated with an increased TEWL, perturbations of the intercellular membranes and an altered epidermal homeostasis ${ }^{(27)}$. Thus, an increased LA supply may contribute to improved skin parameters. ALA and GLA may also affect skin homeostasis along this line.

Modulation of skin properties has been shown for several other nutrients ${ }^{(3,4)}$, indicating that dietary intervention is a way of improving skin conditions and providing protection. It should be stated that effects are moderate and develop over a long-term period.

\section{Acknowledgements}

H. S. is a Fellow of the National Foundation for Cancer Research (NFCR), Bethesda, MD.

S. D. S. holds a scholarship of the GK 1033 (DFG). We thank A. Grieger for statistical analyses and M. Wiebusch for technical assistance. S. D. S. was responsible for the blood analyses, evaluation and interpretation of the data, statistics and was involved in drafting and writing the article. W. S. was responsible for the development of the study design, interpretation of the data, supervision of the analytical work, drafting and writing of the manuscript. H. T. and H. S. were involved in the conception of the study design, supervison of skin analyses, writing and final approval of the article. M. B. and J.-M. M. were responsible for the development of the study design, involved in the interpretation of the data, conception of the article and final approval of the manuscript. U. H. was responsible for the development of the study design, performance and control of skin measurements, interpretation and evaluation of the data, drafting and writing the manuscript. None of the authors had a personal or financial conflict of interest. 


\section{References}

1. Afaq F \& Mukhtar H (2006) Botanical antioxidants in the prevention of photocarcinogenesis and photoaging. Exp Dermatol 15, 678-684.

2. Sies H \& Stahl W (2004) Nutritional protection against skin damage from sunlight. Annu Rev Nutr 24, 173-200.

3. Heinrich U, Neukam K, Tronnier H, Sies H \& Stahl W (2006) Long-term ingestion of high flavanol cocoa provides photoprotection against UV-induced erythema and improves skin condition in women. $J$ Nutr 136, 1565-1569.

4. Stahl W, Heinrich U, Aust O, Tronnier H \& Sies H (2006) Lycopene-rich products and dietary photoprotection. Photochem Photobiol Sci 5, 238-242.

5. Rhodes LE, O'Farrell S, Jackson MJ \& Friedmann PS (1994) Dietary fish-oil supplementation in humans reduces UVBerythemal sensitivity but increases epidermal lipid peroxidation. J Invest Dermatol 103, 151-154.

6. Black HS \& Rhodes LE (2006) The potential of omega-3 fatty acids in the prevention of non-melanoma skin cancer. Cancer Detect Prev 30, 224-232.

7. Ziboh VA, Miller CC \& Cho Y (2000) Metabolism of polyunsaturated fatty acids by skin epidermal enzymes: generation of antiinflammatory and antiproliferative metabolites. Am J Clin Nutr 71, 361S-366S.

8. Rosella O, Sinclair A \& Gibson PR (2000) Polyunsaturated fatty acids reduce non-receptor-mediated transcellular permeation of protein across a model of intestinal epithelium in vitro. J Gastroenterol Hepatol 15, 626-631.

9. Pepe $S$ (2005) Effect of dietary polyunsaturated fatty acids on age-related changes in cardiac mitochondrial membranes. Exp Gerontol 40, 751-758.

10. Proksch E, Holleran WM, Menon GK, Elias PM \& Feingold KR (1993) Barrier function regulates epidermal lipid and DNA synthesis. Br J Dermatol 128, 473-482.

11. Ziboh VA, Cho Y, Mani I \& Xi S (2002) Biological significance of essential fatty acids/prostanoids/lipoxygenase-derived monohydroxy fatty acids in the skin. Arch Pharm Res 25, $747-758$.

12. Brosche T \& Platt D (2000) Effect of borage oil consumption on fatty acid metabolism, transepidermal water loss and skin parameters in elderly people. Arch Gerontol Geriatr 30, $139-150$

13. Hou SY, Mitra AK, White SH, Menon GK, Ghadially R \& Elias PM (1991) Membrane structures in normal and essential fatty acid-deficient stratum corneum: characterization by ruthenium tetroxide staining and X-ray diffraction. J Invest Dermatol 96, $215-223$
14. James MJ, Gibson RA \& Cleland LG (2000) Dietary polyunsaturated fatty acids and inflammatory mediator production. Am J Clin Nutr 71, 343S-348S.

15. Heinrich U, Koop U, Leneveu-Duchemin MC, et al. (2003) Multicenter comparison of skin hydration in terms of physical-, physiological- and product-dependent parameters by the capacitive method (Corneometer CM 825). Int J Cosm Sci 25, 45-53.

16. Folch J \& Lees M (1951) Proteolipides, a new type of tissue lipoproteins; their isolation from brain. J Biol Chem 191, 807-817.

17. Primavera G \& Berardesca E (2005) Sensitive skin: mechanism and diagnosis. Int $J$ Cosmet Sci 27, 1-10.

18. Rodrigues LM, Pinto PC, Magro JM, Fernandes M \& Alves J (2004) Exploring the influence of skin perfusion on transepidermal water loss. Skin Res Techn 10, 257-262.

19. Tronnier H, Wiebusch M, Heinrich U \& Stute R (1999) Surface evaluation of living skin. Adv Exp Med Biol 455, 507-516.

20. Sanders TA \& Younger KM (1981) The effect of dietary supplements of omega 3 polyunsaturated fatty acids on the fatty acid composition of platelets and plasma choline phosphoglycerides. Br J Nutr 45, 613-616.

21. Burdge GC \& Calder PC (2005) Conversion of $\alpha$-linolenic acid to longer-chain polyunsaturated fatty acids in human adults. Reprod Nutr Dev 45, 581-597.

22. Calder PC (2006) n-3 Polyunsaturated fatty acids, inflammation and inflammatory diseases. Am J Clin Nutr 83, Suppl., $1505-1519$.

23. Ren J \& Chung SH (2007) Anti-inflammatory effect of $\alpha$-linolenic acid and its mode of action through inhibition of nitric oxide production and inducible nitric oxide synthase gene expression via $\mathrm{NF}-\kappa \mathrm{B}$ and mitogen-activated protein kinase pathway. J Agric Food Chem 55, 5073-5080.

24. Dooper MM, van Riel B, Graus YM \& M'Rabet L (2003) Dihomogamma-linolenic acid inhibits tumour necrosis factor-alpha production by human leucocytes independently of cyclooxygenase activity. Immunology 110, 348-357.

25. Muggli R (2005) Systemic evening primrose oil improves the biophysical skin parameters of healthy adults. Int J Cosm Sci 27, 243-249.

26. Wertz PW, Abraham W, Cho ES \& Downing DT (1986) Linoleate- rich o-acylsphingolipids of mammalian epidermis: structures and effects of essential fatty acid deficiency. Prog Lipid Res 25, 383-389.

27. Schreiner V, Gooris GS, Pfeiffer S, Lanzendörfer G, Wenck H, Diembeck W, Proksch E \& Bouwstra J (2000) Barrier characteristics of different human skin types investigated with X-ray diffraction, lipid analysis, and electron microscopy imaging. J Invest Dermatol 114, 654-660. 